Knowing in practice: Re-conceptualising vocational expertise

Stephen Billett

School of Vocational, Technology and Arts Education

Faculty of Education, Griffith University

NATHAN 4111

Australia

Ph (61) 738755855

Fax (61) 738756868

Email s.billett@mailbox.gu.edu.au

Billett S (2001) Knowing in practice: Re-conceptualising vocational expertise Learning and Instruction 11 (6) 431-452. 


\section{Knowing in practice: Re-conceptualising vocational expertise}

The following re-conceptualisation of vocational expertise is premised on reconciling contributions from cognitive psychology with those from social and cultural theories of thinking and acting. Relations between the individuals acting and the social practice in which they act are proposed as bases for knowing and performance --- knowing in practice. Domains of knowledge are held to be products of reciprocal and interpretative construction arising from individuals' engagement in social practice, rather than being abstracted disciplinary knowledge or disembedded sociocultural tools. The construction of the individuals' domains of vocational practice is constituted reciprocally through their participation at work. Some implications for curriculum are also proposed.

\section{Introduction}

To date, views about expertise have largely been a product of theorising within cognitive psychology. This discipline has come to characterise expertise as the product of the breadth and organisation of individuals' domain-specific knowledge comprising orders of procedures and levels of conceptual knowledge. Through work within this discipline over a period of three decades, expertise has come to be associated with the development of cognitive structures inside the head that can be applied skilfully in resolving problems associated with a domain of knowledge held as a long-standing truth. In this view, representations of knowledge held in memory are seen as being analogous to tools that can be applied to particular situations or impasses. However, resistance is mounting to the idea that the mind is located solely in the head and remote from the world beyond the skin (e.g. Scribner, 1997/1988; Wertsch, 1998). Not the least is the concern that performance in one situation does not predict performance in another, within the same domain of knowledge. Recent theorising has increasingly projected the mind into social practice and explored the relations between them. A non-dualist view is becoming more accepted, premised on the inseparability of relationships between individuals' knowing and the social world in which they think and act (Rogoff, 1990; Scribner \& Beach, 1993) and a concern to understand these relationships further (Scribner, 1997/1988). Some suggest a need to cast off dualism and the strong individual and mentalistic focus that has emerged from within cognitive psychology (e.g. Greeno, 1997; Hutchins, 1991). Some also propose that the individual's contribution to this relationship represents no more than one component in the process of knowing that is distributed (Pea, 1993) or stretched (Lave, 1991) across social partners and artefacts. Others treat social determinism more cautiously, holding that cognition is both premised on individuals acting in socially-determined activities and sometimes separate from the physical circumstances (e.g. Cobb, 1998; Salomon, 1994), thereby locating roles for both individuals and social practice. The tension resides in the focus being on either capacities or practice (Pelissier, 1991) or on relations between the two. This leaves a conception of expertise that accounts for relations between the mind and social practice yet to be stated, and invites a reappraisal of current conceptions of 
expertise. The conception of expertise founded in mainstream American cognitive psychology based on individuals' acquisition and organisation of domain-specific knowledge in memory sits uneasily with emerging views that include, emphasise or give primacy to the social and cultural contributions and their relationships to thinking, acting and knowing. With its focus on the internal processes of the mind, cognitive psychology is, on its own, unable to provide a comprehensive conception of expertise as it fails to account for the sources of knowledge, and their formation and transformations in the social world. Attempts to redress this positioning have guided recent work within the cognitive perspective (e.g. Resnick et al., 1991; Resnick et al., 1997). However, these are seen by some as attempts to merely contextualise cognitive theorising and as failing to enact fundamental shifts from viewing cognitive structures as acting 'on' to acting 'in' the social world (see Cobb, 1998).

Taking these concerns, a conception of expertise is advanced that is locatable in the dynamic activities of social practices. It proposes how individuals come to know and act by drawing on cognitive, sociocultural and anthropological conceptions, and through an appraisal of the ontological premises of domains of knowledge. The interpsychological processes for developing expertise are held to be constituted reciprocally between the affordance of the social practice and how individuals act and come to know in the social practice. More than contextualising the cognitive account of expertise, relationships among social practice, activities and individual cognition are proposed as being central to this conception of expertise. Accordingly, it attempts to locate a path between the "twin hazards" of individual constructivism (particularly when portrayed as being overly mentalistic) and social determinism (Miller \& Goodnow, 1995).

Individuals' construction of the knowledge that comprises a situated domain of expertise is founded in interpsychological processes of how individuals act within social practice, as this interaction interdependently engages knowledge with historical, cultural and situational geneses. This interdependence between the social practice and those who act within it (Lave, 1991) may be contested (Billett, 1995b) or resisted (Hodges, 1998). Consequently, individuals' interactions with workplaces and the developments arising from these interactions are premised on participation in negotiated forms of engagement in work practice. Over time, these interpsychological processes result in the formation of intrapsychological attributes. However, as Vygotsky (1978) proposes, intrapsychological outcomes are a " result of a long series of developmental events” (1978: 57) and the "process being transformed continues to exist and to change as an external form of activity before definitively turning inward” (1978: 57). Therefore, social situations --- such as workplaces -- are not just one-off sources of learning and knowing. Instead, they constitute environments in which knowing and learning are co-constructed through ongoing and reciprocal processes (Rogoff, 1995; Valsiner, 1994). 
In considering individuals' cognition, the term 'knowing' is used to link learning with thinking and acting and to connote it as something projected out 'beyond the skin' (Wertsch, 1991; Hutchins, 1991), rather than as an internal process of the mind. 'Knowing' also assists a shift away from categories of knowledge (i.e. declarative, procedural) portrayed as entities that act upon, rather than those whose purpose and development is premised on acting within the social world. The concept of 'knowing' also draws together processes separately described in the cognitive literature as problem-solving, learning and transfer, representing intrapsychological attributes as processes rather than fixed structures. This conception of knowing has a different emphasis than Schon's (1983) knowing in action, which draws upon Ryle's (1949) consideration of knowledge 'how'. Here, knowing is held to be an active and reciprocal process engaging with the world beyond the physical self and drawing together both knowledge 'how, and knowledge 'that'.

In proposing this view of expertise and its development, an initial discussion of domains of knowledge is used to consider the nature and organisation of the knowledge comprising expertise. Reviews of cognitive and sociocultural views of expertise follow. Drawing upon these two constructivist perspectives, and with contributions from anthropology and cultural psychology, a re-conceptualisation of expertise is then advanced. This reconceptualisation acknowledges the relational, reciprocal, embedded, pertinent and situational requirements for knowing and acting at the level of expertise.

\section{Domains of knowledge}

The term 'domain of knowledge' has multiple definitions. It is often used to describe a specific field of study, such as biology or economics (Alexander et al., 1991). Consistent with the cognitive perspective, Alexander and Judy (1988) define domains of knowledge as the declarative, procedural and conditional knowledge one possesses in relation to a field of study. From this view, individuals are expert because their knowledge is organised consistently with the principles of an academic discipline (Gelman \& Greeno, 1989) and can resolve problems in ways consistent with the discipline. The term 'domain' is also defined as the rule-based procedural nature of a field (Scandura, 1980). This definition also suggests that a domain is an objective entity, which exists external to and is separable from individuals' cognitive structures. Nevertheless, as Säljö (1999) points out, this concept of a domain represents a first step by cognitive psychology towards accepting a social basis for cognition. One issue, therefore, is whether to view knowledge itself as an epistemological truth --- an absolute --- or whether it should be seen as the idiosyncratic product of individuals' histories (Alexander et al., 1991). The former seems to be adopted and persisted with in mainstream cognitive accounts of expertise (e.g. Ericsson \& Lehmann, 1996; Ericsson \& Smith, 1991). The latter view is more consonant with the constructivist underpinnings of both cognitive and sociocultural theories. However, definitions and views within cognitive psychology and sociocultural theory tend to portray knowledge as comprising long-standing truths (Prawat \& Floden, 1994). For instance, Ericsson and Smith (1991) propose 
domains as bodies of knowledge that transcend particular circumstances and from which performance can be gauged by subjects undertaking representative domain-related tasks in standardised laboratory conditions. They also refer to 'traditional domains', thereby positioning them as long-standing truths. Similarly, the sociocultural line of development in reflecting a cultural need is also disembedded from practice.

There seem to be at least two reasons why individuals' interpretative construction of knowledge is not reducible to some uniform base of knowledge --- an absolute truth (Prawat \& Floden, 1994). Firstly, even a common social practice, such as a vocation, is enacted differently across social circumstances (Billett, 1995a), which results in these different manifestations of the vocational domain. These manifestations suggest that 'long-standing truths' may constitute an abstracted domain and contribute their historical and cultural legacy to enacted practice. However, their contributions are likely to be manifested in different ways by different kinds of social practice, such as particular workplaces or work practices. Secondly, individuals' interpretations of what they experience are likely to be quite idiosyncratic (Newman et al., 1989). Even if 'objective' truth were accessible, it would be constructed interpretatively by learners, premised on their personal histories or ontogenies. How individuals know and make sense of what they experience is premised on their ontogenies. Therefore, it is necessary to view domains not only as abstracted long-held truths, but also as constituted by situational factors and also how individuals construct their conceptions or domains of these situationally based requirements for performance, based on their socially constituted ontogenies.

\section{Cognitive view of expertise: Capacities}

The cognitive psychology view of expertise places primacy on the breadth and organisation of individuals' domain-specific knowledge in solving problems and overcoming impasses. These attributes are central to the hallmark of expertise: the capacity to perform non-routine tasks within a domain of knowledge. Key differences between experts and novices in the performance of these tasks are premised on the organisation of their domain-specific knowledge, not necessarily the ability to process that knowledge (Glaser, 1984; Sweller, 1989; Wagner \& Sternberg, 1986). The organisation of experts' knowledge around salient domain-based principles enhances the prospect for problem solving and transfer (Chi et al., 1981; Groen \& Patel, 1988). Unlike novices, who may respond to the superficial surface features of problems, experts' knowledge is held to be deeply structured and indexed, thereby permitting successful non-routine problem solving (Gott, 1989; Lesgold, 1989). Deep structuring comprises associations and links among knowledge. Indexing refers to associations between knowledge and the circumstances of its deployment, which in turn eases the subsequent recall and redeployment of knowledge (Ericsson \& Simon, 1984). As with domain-specificity, indexing can be held to link the organisation of knowledge to the social practice. So efficacy in organising knowledge for its re-deployment is seen as a key determinant in problem solving within the cognitive view. Consequently, learning from this perspective is not only associated with the acquisition of 
knowledge, but also its organisation (Prawat, 1989). Cognitive theory has long proposed that a strong motivation in humans is to systemise the knowledge being learnt. This systemisation is premised on discrimination within and the modification of knowledge in order to resolve disequilibrium experienced through encounters (stimuli) with the social world (Piaget, 1966). For instance, the richness of the organisation and associations between concepts, propositions, facts and assertions permits their access and subsequent utilisation (Groen \& Patel, 1988). Systematising and structuring are therefore salient concepts within cognitive views about domains of knowledge and expertise. However, the source of this structuring and the basis for systemisation are contentious.

So, within the cognitive project, the evidence is weighted towards the organisation and connectedness of individuals' domain-specific knowledge as being salient for performance. However, the bases for performance are not restricted to contributions within the head. For example, chess experts have been shown to possess remarkable memories for chess positions when these positions are the product of chess games (Simon \& Gilmartin, 1973). Their representations of chess positions are based on chunks of data retrieved simultaneously and are related spatially premised on the individual positioning of pieces. So, although experts' knowledge is premised around sets of key principles - rules and practices of Chess (Chi et al., 1981), the basis for the recall and deployment of their knowledge is premised on situational factors --- the unfolding game of chess. This conclusion is supported by other work showing that chess experts, despite their remarkable memories, are no better than novices when asked to recall random positioning of chess pieces (Chase \& Simon, 1973). Therefore, although experts' knowledge is organised by rule-based domains of knowledge, these domains are not remote from social practice, instead being manifested --- at least in part --- from situational factors comprising the evolving games of chess. Yet, as noted, domains within cognitive research are often proposed as being academic disciplines portrayed as epistemological or 'long-standing' truths (Alexander et al., 1991).

The potency of domain-specific knowledge is also evident in cognitive activities that are seen as being of a more general kind. Significant concerns are at stake here. The case for non-specific and universally applicable approaches to complex thinking is often central to the goals of general educational programs. However, there is interdependence (at least) between domain-specific knowledge and that knowledge which is seen to posses a more executive or general role. Investigations of chess players (Chi, 1978), street vendors (Carraher et al., 1985), horse racing handicappers (Ceci \& Liker, 1986), abacus counters (Stigler et al., 1982), chess experts (Chase \& Simon, 1973; Simon \& Gilmartin, 1973) physics experts (Chi, et al., 1982), hospitality workers (Stevenson, 1996) and airline counter workers (Beven, 1997) have provided evidence of the significant role of domain-specific knowledge in complex thinking, rather than general procedures. The domain specificity in these studies is linked directly to particular social practice.

For instance, Ceci and Liker (1986) investigated the performance of horse racing handicappers, whose work requires the synthesis of a range of information and predictions of likely 
outcomes. The subjects were nominated as being either expert or non-expert on their frequency of success in predicting handicaps in horse races. There was no correlation amongst age, experience with handicapping and successful handicapping. Subjects were tested using the Weschler Adult Intelligence Scale (WAIS), which correlates with the Full Scale IQ test (Ceci \& Liker, 1986). The findings indicated no correlation between performance on these scales and expert or novice classifications. Therefore, general ability of the subjects was not a predictor of success. Another study, comparing responses to economics problems between college-educated students and subjects who had learnt their economics knowledge in the workplace, produced similar findings (Voss et al., 1983). The collegeeducated students performed better than their workplace-prepared counterparts when answering questions about economics, but floundered when faced with real work tasks. The workplace-prepared subjects did exceptionally well on the latter categories of tasks.

A common factor, in these two studies and acknowledged in a recent review (Ericsson \& Lehmann, 1996) is that the existence of strong generalised processing ability alone, as indicated on an intelligence test, is not a sufficient quality for successful performance. The expert handicappers in Ceci and Liker's (1986) study, and workplace learners in Voss et al.'s (1983) study required the integrated use of both strategic and highly specific forms of knowledge, embedded in a particular domain of activity. Similarly, Schraagen (1993) found that, whereas experienced scientists could develop research designs for familiar problems, they could not do so in unfamiliar areas. Studies of hospitality workers concluded that not only the goals for performance, but much of the knowledge required for performance, was quite situationally specific (Stevenson, 1996). Similar findings were advanced from investigations of airline counter workers (Beven, 1997). These studies illustrate the significant role of domain-specific knowledge in the performance at work, and either the invisibility or low level of contribution provided by more general competencies. Further, these findings point to the indivisibility between social practice and domains of knowledge that are manifested in particular ways in these social practices. For instance, basketball referees were able to identify categories of fouls more effectively than basketball players or coaches (Allard et al., 1991 cited in Ericsson \& Lehmann, 1996).

From what has been advanced above, domain specificity is salient for demanding thinking and acting, such as non-routine problem solving in everyday work activities. Therefore, contributions from the cognitive view are useful for understanding and identifying the attributes required for performance in goal-directed activities. Nevertheless, this view does little to account for the origins of these domains, nor for how individuals construct socially sourced knowledge in the forms of domains (Laufer \& Glick, 1996). Yet, such is the interdependence in relationship between cognitive activities and the social world, that it possible to identify ways in which individuals' construction of knowledge is structured by the goal-directed activities in which they engage. In illustrating this relationship, at least six bases can be identified from the cognitive literature (Billett, 1996). Firstly, the domainspecificity of expertise is associated with social practice. Consequently, salient principles which are indexed to social practice reflect the domain's social genesis. Secondly, the knowledge constructed 
through problem-solving is focused on resolving impasses set in the social world. Third, compilation of procedures and chunking of concepts is the result of ongoing engagement with socially-determined tasks. Fourth, transfer is socially and culturally constructed. Fifth, individuals' efforts are relational to social practice with some tasks extracting a more effortful response than others. And finally, socially determined dispositional factors are relational to cognitive structures and activities. Accordingly, the domain of knowledge and individuals' learning of that knowledge, which includes its organisation and associations necessary for performance, are founded in relations with social practice. For instance, take the hallmark of expertise, success in non-routine problem solving within a domain. Beyond individuals' familiarity with the activity, routineness will be determined by the norms of particular social practice (e.g. workplaces) as will judgments about the worth of solutions to those problems. In terms of vocational practice, the kinds of problems and what constitutes non-routine tasks will be located in particular instances of the vocational practice. For example, with automotive mechanics' work, the routineness of workplace tasks will differ according the requirements of the work practice. In a major city dealership, where mechanics might work on only one or two makes of vehicles which may be under warranty, an expedient response to a faulty vehicle component might be replacement with another. However, in a garage in a small rural town, where mechanics work on all kinds, makes and ages of vehicles, and where spare parts are not easily sourced, a successful solution might be to repair the component part or fabricate another. So, whereas the cognitive view makes important contributions to understanding expert performance, the concept of domains advanced by this discipline needs extending to include those that can account for their source and development.

\section{Social and cultural conceptions of expertise: Practice}

Despite its prominence in the literature, the cognitive perspective does not monopolise views about what constitutes expertise. Other perspectives also offer important contributions. The sociocultural literature emphasises domains of social and cultural needs embedded in distinct lines of development within social practice (Scribner, 1985). From an anthropological perspective, Lave and Wenger (1991) refer to expertise as being ongoing movement towards full participation and the formation of identity within a particular community of practice, which is constantly evolving (Lave, 1993). In a similar way, Goodnow (1990) uses cultural psychology to make complementary contributions referring to the appropriateness of particular behaviour in culturally determined activities. These views emphasise particular social practice as the premise for expertise and as something arising through participation in the social practice: 'knowing in practice'. These perspectives offer more than an alternative to the cognitive perspective, because they also offer ways of understanding the relationships between social practice and the mind.

Sociocultural theory holds that the organisation and construction of knowledge are socially and culturally constituted. Within the sociocultural approach (Wertsch, 1991), or what Cole (1998) refers to as cultural history activity theory, four lines of the evolving social development of knowledge 
are identified (e.g. Cole, 1998; Rogoff, 1990; Scribner, 1985;). These are: the phylogenetic --- the contribution to knowledge arising from the evolving history of the human species; the sociocultural --the particular requirements of evolving cultural practice (e.g. a vocation); the ontogenetic --- the ongoing products of individuals' learning throughout their lives through interaction with the social world; and the microgenetic --- the moment-by-moment learning of individuals. However, just as the domains of knowledge advanced in cognitive theory are abstracted epistemological truths, the sociocultural level of development is also disembedded from circumstances where individuals enact goal-directed activities. Sociocultural practice, which embodies cultural need, is remote and disembedded from actual practice just as the conception of a vocation (e.g. hairdresser, plumber, doctor) is disembedded from what occurs in the enactment of the vocation. This line of sociogenesis reflects cultural need (the vocation) rather than the exigencies of the enactment of that practice. It is at the situational level that the goal-directed vocational activities are shaped, albeit influenced by historical and sociocultural lines of development. The requirements of a particular vocational practice (e.g. in a particular hairdressing salon, medical practice, garage, coal mine) influence how the disembedded knowledge of the occupation is manifested in practice. Engestrom and Middleton (1996) refer to microsociological approaches, contexts and structuring of work as the product of local interactions and negotiations. Suchman (1996) similarly points to "a local order of familiar equipment and practices, specifically constituted for the work at hand.” (1996: 56) To account for the circumstances which furnish the goal-directed activities that individuals engage in and judgments about how these activities have been undertaken, the situational level warrants inclusion as a line of development within sociocultural theory. This directly acknowledges the contributions of situational factors where the historical and culturally derived knowledge is deployed and manifested in actual practice, as in cognitive accounts. The requirements of social practices (e.g. the workplace or work practice) can be understood by their activity systems (Engestrom, 1993) (e.g. division of labour, community, objects and rules) that determine how activities in particular work practice proceed. Moreover, given the range of factors comprising the activity system, the social practice, the activities within it and the requirements for performance are likely to be unique in some ways (Billett, 1998). These claims are supported by the kinds of analysis that Suchman $(1996,1997)$, provides in her accounts of an airport operations room where the activities are the product of the individuals and artefacts constitute a locally ordered work setting that is not pre-determined not static, but is continually re-constituting itself.

Therefore, if complexes of situational factors differentiate particular social practice (such as workplaces), what comprises expertise will be conceptualised in different ways across communities of work practice (Wenger, 1998), because requirements for performance are founded in the social practice. This is the case even when an activity that is conceptually similar at the sociocultural level (e.g. an occupation), is being undertaken. Situational factors associated with the expert enactment of knowledge go beyond the possession of sociocultural technical skills or tools (e.g. cutting hair, 
diagnosing a patient). Instead, these factors influence how these skills are manifested in a particular circumstance. Because of this, acceptable practice in one workplace may be quite inappropriate in another, as procedures are different and the goals for performance may be quite distinct. These factors influence not only the activities individuals engage in, but also what is taken as expert performance.

In an investigation of work activities in four hairdressing salons, the goals for and bases of participation in hairdressing activities were determined by factors comprising the internal press of the workplace and external demands of the client community (Billett, 1995a). In each salon, the goals for hairdressing had distinctive features. Given the same set of hairdressing problems to resolve, hairdressers in each salon fashioned responses that had consistency across and within the salons as well as some individual variations. Therefore, some components of the responses were consonant with the goals and norms of the sociocultural practice (hairdressing), while others were those of the particular salons (situational manifestations of practice) and some idiosyncrasies arising from the hairdressers' ontogenies. Observation revealed the characteristics of the vocational practice included what comprised performance in each salon. In a fashionable inner city salon, the key goals for performance were to transform the clients' appearance, and to offer new cuts and colours. The interaction with clients in this salon was a product of the clientele and the interests and values (lifestyle) of the hairdressers. In a salon in a low socio-economic suburb, the requirements for performance were to manage a precarious business with an absent owner, two part-time senior hairdressers and a clientele that included those who demanded complex treatments, yet did not subsequently care for their hair. A key requirement here was to manage these 'awkward' customers when they returned complaining vociferously and forcefully about their treatments. In another salon, the clientele comprised elderly women who came for companionship as much as for hair treatments. Here, the hairdressers' knowledge of clients' personal histories, knowing the names and circumstances of family and friends, was an important component of practice. The fourth salon was in a provincial town in a rural region that was enduring a three-year drought. The goals here included providing good value to maintain the clientele and managing the difficult balance between eliciting additional service (colours and perms) yet not causing clients to choose between the cost of a hair treatment and groceries for home.

The factors that constitute the social practice within each of the salons are identifiable by and may be explained through their activity systems that included the division of labour, rules and norms, relationships with the client community and the degree of internal cohesion. Each site had particular goals associated with the division of labour. For example, one salon had a rule that hairdressers should engage in tasks, as they became available, whose complexity was most consistent with their level of skills. These were part of the particular work practice insisted upon by the owner-manager. This resulted in clients frequently being swapped among hairdressers, as 
tasks of greater accountability became available. At the salon in the low socio-economic suburb, there was some disagreement among the staff' about their conception of hairdressing. However, these differences were subordinated by common concerns about the 'awkward' clients and security of employment. So there were concepts and procedures of the vocational practice that were common to each instance of vocational practice, the product of their activity systems (Engestrom 1993) and local negotiations (Suchman, 1996). Indeed, how these common views were negotiated also differed across these social practices. For example, in the trendy salon there were common values about hairdressing which were different from the almost familial atmosphere of another salon, which had different mores and values about hairdressing. In a third, there was a rigid form of internal press associated with the authority and presence of the owner-manager. For instance, the hairdressers operated under the owner's rule of 'no-yappers'. The hairdressing was to proceed in silence unless clients initiated conversations. The hairdressers in this salon developed a set of signals by which they communicated non-verbally. These mores led to particular work strategies being developed in this salon, some primarily associated with responding to idiosyncratic demands of the owner. The work in this salon progressed in comparative silence compared with the exchanges that occurred in the other salons and which were part of the rationale for the hairdressers' work in the salon that catered to elderly women. In these ways, local negotiations (Suchman, 1996) determined the goals for practice.

Similar situationally specific notions of competence were observable in open cut coal mines (Billett, 1995b). Even across mines owned by the same company, some of them on adjacent leases, there were different requirements for performance. These were premised on the history of ownership, different demarcations of work, historically entrenched work practices, the mine's age and the mine's location in the coal-bearing basin. Consequently, conceptions of expert performance are not uniform across these workplaces, with the differences being accounted for by the activity systems of these communities of work practice.

Individuals' engagement in work practice has consequences for accessing and learning situationally constituted knowledge. The work practice in each salon afforded quite different access to novices and experienced hairdressers alike and made different demands, with different consequences, for what they learnt. One variable was size. In smaller salons, the apprentices had responsibility for a wider range of activities earlier than in the larger ones. Another was culture of practice (Brown et al., 1989). In the trendy salon, each hairdresser worked on their own clients from greeting them at the door to getting them coffee, washing their hair, negotiating with them and styling their hair. So it was incumbent on the apprentice in this salon to take sole responsibility for clients as soon as possible. In another salon, key work tasks were divided among the hairdressers, and the apprentices were more focused on support and preparatory activities until their final year. There was also a privileging of particular knowledge amongst settings (Goodnow, 1990), some of which remained the sole domain of principal participants. For example, two owner- 
managers maintained control over the ordering and management of stock. Therefore, in these salons, even senior hairdressers were denied the experience of managing stock. Yet, at another salon, the apprentice's role included checking and ordering stock. Consequently, although engaged in a common sociocultural practice, the salons not only had quite different requirements for expertise, but the way they afforded participation also differed.

Expertise needs to be considered situationally, being related to the circumstances of the enactment of the vocational practice. This does not mean that the individual's capacity to perform is welded to one setting. Rather, it recognises that expertise can only be understood within particular domains of knowledge and action (social practice), thus embedding it in particular social circumstances. Perhaps there is no such thing as a vocational expert per se, only those who are able to resolve non-routine and routine problems constituted by particular workplaces. For example, a hairdresser who might be expert in an inner city salon may not have some of the attributes required to be judged as an expert in one of the other salons. These characterisations are held to be qualities of expertise as situative phenomena. However, they constitute only one side of the interdependent relationship required for knowing at work. How individuals act in the social practice, thereby coming to know in ways that permit them to participate fully, and how they construct their domain of knowledge also reside with the individual. Therefore, the other dimension of the interdependence or interpsychological process is how individuals participate and construct knowledge.

\section{Individuals’ participation and construction: Knowing in practice}

The knowledge to be constructed by individuals and the means of that construction can be understood in terms of interdependence between the situation that comprises a domain of activities and goals, and the individuals acting in the social practice. This suggests that this knowledge, with its historical and cultural geneses, is manifested in particular ways in work practice, and that ultimately individuals' appropriation of this embedded knowledge is interpretative or co-constructed (Valsiner, 1994; Wertsch, 1998). Accordingly, conceptions of domains need to include the individually constructed rule-system (procedures) and related conceptual knowledge (propositions), mediated by the socially derived circumstances in which they were deployed and appropriated interpsychologically. Over time, individuals' situationally constructed domains of knowledge may become increasingly intersubjective when knowledge is shared with others, thereby engendering common aspects (Newman et al., 1989). However, it is unrealistic to expect complete concurrence and it is unlikely that knowledge that is opaque or not likely to be discussed will become intersubjective. Concept maps of the task of hair colouring generated by hairdressers in the four salons revealed much that was common (Billett, 1995a) at the superstructure level of their conceptual organisation (Groen \& Patel, 1988). However, the microstructures of these concept maps were quite idiosyncratic. With concept maps of hair structures, the representations of the hairdressers' knowledge were almost wholly idiosyncratic. The hairdressers claimed the differences were associated with the fact that hair colouring was discussed in the 
workplace, whereas 'hair structures' were not talked about in the salons. Perhaps the reason for this is that hair structures are opaque and not accessible in hairdressing salons. Interestingly, the hairdressers claimed to associate concepts of hair structures with a different kind of social source: theory classes in technical colleges. Yet opportunities to develop intersubjectivity - for instance, with hair colouring do not mean that individuals will construct this knowledge wholly intersubjectively because idiosyncratic personal histories or ontogenies shape their constructions of knowledge (Billett, 1997). For instance, an English hairdresser working in Australia provided an atypical response to one problem. When asked about this response, the Australian hairdressers suggested that the solution was not appropriate in a hot climate where many clients spent time in chlorinated swimming pools. Further, as social practices are constantly transforming, the range of factors that determine the activity system must inevitably change over time. Whereas the sociocultural line of development reflects changing cultural needs (e.g. growing resistance to using chemicals in hairdressing), the situational level responds to factors at the level of the enactment of practice, which are themselves transforming. This transformation is ongoing because social practice such as that which occurs in workplaces is constantly being changed by the requirements of those who are the objects of its activities, those who work in them, the changing division of labour, relationships, and the norms and practices that constitute its activity systems (Engestrom \& Middleton 1996; Suchman, 1996). For instance, since the investigation of the four hairdressing salons was completed, at least two of the salons have had a change of their ownership and significant changes in staff. It is within these constantly transforming situative domains of practice located in these workplaces that individuals engage in microgenetic development (moment-by-moment learning) (Rogoff, 1995), through their participation in goal-directed activities. Therefore, individuals' interactions and negotiations within the social practice and their ability to maintain their participation represent an ongoing and evolving process. Individuals acting in social practice construct domains of knowledge; the construction of these domains is also mediated by their personal histories (e.g. their existing knowledge) and by the access to the activities of the particular social practice(s).

This view of knowing in practice is quite distinct from those suggesting that domains of knowledge required for performance are objective bodies of knowledge, such as an academic disciplines or fields of study, not subject to interdependence among cultural need, social practice and individual interaction. Further, the degree to which hairdressers might be interested in being experts in a particular salon may well determine how they act in that social practice --- how their domains of vocational practice are shaped. Having been able to map the hairdressers' interests and motivations, it seems improbable that some of them would be able to, or even be interested in, working in some of the other salons. Indeed, some hairdressers had deliberately self-selected and sought out their place of employment. Even under duress of the kind that was evident in one salon, they would most likely engage in mastery rather than appropriation of the knowledge accessed in the workplace (Wertsch, 1998). Despite the owner's insistence that he knew best, the apprentices reported learning from other 
apprentices with whom they interacted at college. These interactions broadened their understanding of procedures of vocational practice. These examples show that expertise is more relational to particular social practice than has perhaps been advanced within cognitive theory. The cognitive view focuses on capacities (cognitive structures, process and memory), while the situational view emphasises interactional systems that include individuals as participants interacting with others, artefacts and objects that comprise the social practice.-

So the contribution of individuals acting in social practice can be understood through a consideration of ontogeny as a product of the accumulation of experiences throughout life. Therefore, rather than being singular or uniform, the construction of knowledge is an interpretative outcome premised on individuals' acting in social practice. Individuals' unique bases of knowledge and ways of knowing are reflexively deployed through goal-directed activities in social practice as they co-construct (Valsiner, 1994) or appropriate (Rogoff, 1995; Wertsch, 1998) knowledge. Accordingly, the development of expertise from this view is characterised by intersections between the trajectories of the transforming social practice and individuals' ontogenetic development. Because of their unique ways of knowing, individuals' conceptions of the requirements for performance will likely be differentiated in some way from others acting in the social practice. Through interactions, greater subjectivity may be realised. Yet there is a dynamic interplay between the evolving requirements for performance in terms of activities and the fit of the individuals' constantly evolving knowledge of that practice. Moreover, securing expertise is both ongoing and contested through individuals' encounters and relations within the social practice, such as in workplaces. Engestrom and Middleton (1996) similarly conclude that expertise now needs to be viewed as the "ongoing collaborative and discursive construction of tasks, solutions, visions, breakdowns and innovations” (1996: 4). So the areas of complementarily between the cognitive and sociocultural theories host an invitation to build upon these theories to understand the relationships between the mind and social practice, rather than not wholly discarding one or the other of these sets of ideas.

Yet is it possible to generalise from the findings of studies of hairdressers and coal miners? Are situated domains likely to be shaped only by particular spatial and shared activities, such as workplaces? Certainly, the kinds of intersubjectivities likely to arise when individuals directly interact in workplaces and at home are potentially of a different kind than where individuals practise their vocation or live in isolation from others. The kinds of coordinated activity that Suchman (1996; 1997) identifies in an airport operations room, discussions in the cockpits of commercial airlines (Hutchins \& Palen, 1997) and those between shift workers in manufacturing (Trognon \& Grusenmeyer, 1997) will likely result in enhanced intersubjectivity between social partners. However, direct interpersonal interactions are not the only set of social factors that shape performance. Scribner (1985) and Rogoff (1990) propose that cultural practices and norms shape even the most apparently solitary activities. Scribner (1985) uses Marx’s example of the solitary lighthouse keeper to illustrate that practices and 
expectations (goals) with historical and social geneses shape even this solitary work. An artist working in the isolation of his studio reported shaping his practice to account for situational factors determining the kinds and purposes of his work that included physical environments and consideration of the market (Billett, 1999). Similarly, Goodnow (1990) claims that academic journals from Europe have quite different character and value different emphases than those from the United States. Hence the requirements for performance are products of different cultural practice. Even a common language has localised and cultural variations, making its enactment in different kinds of circumstances subject to particular requirements and knowledge about how to proceed. Perhaps the sociogenesis is strongest when individuals can encounter the direct guidance that makes shared understanding of historically, culturally and situationally constituted practice highly accessible and where practice is physically situated to afford models and access to cultural practices. Nevertheless, even the vocational practitioner who works alone (e.g. the concert pianist) is likely to be confronted by expectations of and requirements for performance that will differ across situations and circumstances (e.g. piano, acoustics, repetoire).

\section{Re-conceptualising expertise}

In re-conceptualising expertise as something that is situated, dynamic, founded in and relational to practice, some of Lave and Wenger's (1991) propositions provide useful starting points. They refer to full participation in a community of practice, rather than expertise. Even then, full participation is shaped by a belief that all practitioners are peripheral in the sense that practice itself is fluid and evolving. Hence there is no such thing as central participation. They propose four qualities for full participation. Firstly, learning about a social practice is realised through the process of becoming a full participant. Access to and participation in the community's activities are necessary bases for the understanding required for full participation. Consequently, engagement over time is required for the appropriation of situationally germane knowledge and skilfulness. In this way, expertise is defined more broadly than the possession of skilful knowledge; it also comprises competence in the norms and cultural practices that sustain and utilise these skills. This view emphasises a focus on the requirement of particular practice, and the need to move from peripheral (novice) to full participation (expertise) within that practice. Third, full participation implies being capable with new activities, performing new tasks and comprehending new understanding (Lave \& Wenger, 1991). This view is consonant with the attributes of experts to be adaptable and transferable (i.e. -the cognitive hallmark of expertise - nonroutine problem solving). Fourth, individuals are defined by, as well as defining, their relationship with the social practice in which they participate. For example, as full participants, senior hairdressers, owners and managers determine how the vocational practice of hairdressing is conducted and what constitutes acceptable performance and the division of labour. This again emphasises the reciprocity within socially determined activities (Rogoff, 1995; Valsiner, 1994). 
As noted, cultural values are also germane to social practice and constitute a need to include these culturally determined dispositional aspects of competence. Goodnow (1990) proposes that competent performance is circumstantial, with some behaviour being seen as being more smart or intelligent than others in given circumstances. Although some behaviour, which would be described as being intelligent, is adaptive and similar across cultures, there will be situationally determined variants. As the view of expertise being proposed emphasises credibility within social practice, it needs to include behaviours and approaches that are likely to be held as being 'intelligent' in the particular circumstances. For instance, there is an expectation of being cool and logical in work planning situations, spontaneous and light in social situations, and emotional in romantic situations (Goodnow, 1990). Also, on some occasions, some approaches to problem solving are better than others. Equally, some problems will be viewed as significant, whilst others are trivial. The significance of problems and the valuing of solutions will be determined by the social and cultural exigencies of the particular practice. Finally, some skills and some areas of knowledge are seen in some communities as belonging to some people more than others. The community of practice determines a hierarchy of tasks (Lave, 1990) and, within that, there may be knowledge reserved for particular groups. This privileging determines access.

Drawing on these social and cultural factors, a tentative conception of expertise that encompasses cognitive, social and cultural dimensions is proposed. Experts' knowledge and its organisation, as conceptualised within the cognitive literature, are subsumed within this view. That is, the organisation and development of knowledge permits individuals to address non-routine problems within a domain of activity. However, more than just being a collection of situated examples of cognitive activity, expertise emphasises the interdependence of the social and cultural influences on this knowledge, the participation in practice required to know, and the strong role played by 'noncognitive' cultural dispositions in performance at work. In these ways, distinctions between practice or capacities (Greeno, 1997; Pelissier, 1991) have been softened by suggesting that these capacities are influenced by and constructed through participation in social practice at intersections between the social practice and individuals' ontogenies. Therefore, the key elements of this conceptualisation of expertise are its relational, embedded, competent, reciprocal and pertinent characteristics. Consequently, it is proposed that expertise:

(i) is relational in terms of requirements of a particular social practice in which it is enacted;

(ii) is embedded, being the product of extensive practise, with meaning about practice derived by becoming a full participant, over time, and with understanding shaped by participation in the activities and norms of that practice;

(iii) comprises competence in the community's discourse, in the routine and non-routine activities, mastery of new understanding, and the ability to perform and adapt existing skills;

(iv) is reciprocal, shaping as well as being shaped, by the community of work practice, which includes setting and maintaining standards of the practice; and 
(v) requires pertinence in the appropriateness of problem solutions, such as knowing what behaviours are acceptable, and in what circumstances, in problem-solving. This quality reflects the values a community of work practice assigns to problems and the appropriate amount of effort and understanding of what knowledge is privileged.

\section{Considerations for curriculum}

A view of expertise as located in particular social practice presents the relationship between what has to be known (i.e. the norms, procedure, and concepts) and the knower (the individual) as a dynamic one. This relationship can be considered in terms of curriculum as pathways of participation in social practice. Such pathways are referred to in both the cognitive and sociocultural literatures. Cognitive psychology posits a pathway to expertise through the acquisition of procedural and conceptual knowledge, organised and richly indexed to facilitate complex thinking activities, such as adaptability, transfer and non-routine problem solving within a socially constituted domain (Gott, 1989; Royer, 1979). A sociocultural pathway to expertise is associated with engagement in particular social practices and seen as a trajectory towards the goal of participating fully, through engagement in tasks of increasing accountability. Over time, this participation leads to the acquisition of 'skilful knowledge', but also to the facility to engage successfully in the discourse, norms and practices of the particular social practice (Engestrom \& Middleton, 1996; Goodnow, 1990; Säljö, 1999), thereby emphasising relations between capacities and practice. Commonality across both perspectives include the construction of knowledge arising through problem-solving that permits successful performance within a specific set of circumstances. The goals within these problem-solving processes are socially sourced, as are procedures used to secure those goals. While both perspectives refer to the application of salient concepts to secure outcomes, the sociocultural and cultural psychology views both emphasise relational aspects of competence. Together, they emphasise that expertise will likely be realised through social circumstances that provide the kinds of problems and solutions that are relational to and authentic within those circumstances. That is, learning experiences that are divorced from those activities and goals found in the circumstances where the knowledge is to be applied (e.g. substitute activities and sites) may not develop the kinds of knowing required to respond successfully to nonroutine tasks. In this view of expertise, novices do not necessarily lack capability. They may, however, lack access to the knowledge within a particular domain of activities (practice) that permits the conceptualisation and categorisation of problems and, consequently, the capacities to secure goals.

Differences amongst social practice and requirements for performance raise further concerns about the potential to transfer knowledge from one setting to another. The complex of situational factors and local negotiations that comprises practice may explain the problem of transfer across situations where the same vocational activity is being conducted. For example, the particular social circumstances of educational institutions and workplaces (those situations where vocational practice is conducted) are rendered quite distant from each other by analyses premised 
on activity as the basis for knowing in practice. Further, accounts of the contributions of situational factors and local negotiations defy the value of highly detailed and prescriptive curricula intents that are increasingly favoured in vocational education, often in behavioural formats (i.e. competency standards). The situational factors also challenge assumptions that knowledge can be understood by decontextualised and abstracted entities (e.g. key or generic competencies). It is the particular complex of factors that gives meaning to problem-solving activities in the community of work practice, and solutions need to account for these factors.

Therefore, developing expertise requires more than a focus on cognitive and sociocultural tools. How those tools are enacted in particular circumstances and activities is crucial. Although shaped by sociocultural sources that convey durable knowledge, this knowledge is also embedded in domains of activities within the social practice, thereby transforming the abstracted knowledge through its application (e.g. the teaching or deployment of academic disciplines). Expertise includes that which permits the resolution of non-routine problems to the satisfaction of the requirements of social practice. Conceptions of curriculum, therefore, need to take into account how goals for performance vary and articulate how it is possible to develop knowledge that is robust enough to transcend the particular workplace. Therefore, in developing robust knowledge in individuals, different conceptions of solutions to problems and their adequacy need to be appraised. Variability in practice needs to be emphasised, with principles and practices identified that assist knowing about different kinds of solutions and evaluations of their appropriateness. For instance, apprentice chefs might learn about different ways of thickening sauces. These ways of knowing would include the application of existing sociocultural practice (e.g. a rue for white sauce and arrowroot for fruit flans), what kinds of thickening are likely to be useful in different kinds of catering (e.g. restaurant and hospital food) and for different kinds of purposes (further thickening a sauce that is too thin, cost considerations). This strengthens the view that it is not sufficient to learn just the knowledge and procedures of sociocultural development. It also elaborates the reasons why learning experiences should also focus on conditions of application of the knowledge and skills to be learnt and how those applications might vary across instances of vocational practice.

\section{Summary}

In sum, a dynamic, negotiated and situated view of expertise is advanced here building upon the contributions from cognitive psychology (e.g. Ericcson \& Lehmann, 1996; Ericsson \& Smith, 1991), anthropology (Lave, 1993; 1991), cultural psychology (Goodnow, 1990) and sociocultural theory (e.g. Cole, 1998; Wertsch, 1991; 1998), and others whose work sits between these disciplines (Rogoff, 1990; 1995). Central to this case is the conception of domains of knowledge. Rather than being epistemological truths with an objective and singular character, such as those associated with academic study, socially determined activities constitute domains of knowledge 
that are shaped by history and culture. In turn, these individuals construct this knowledge as personally structured and organised domains, which may become increasingly intersubjective if shared through interpsychological processes in workplaces. Both cognitive psychology and sociocultural theory advance conceptions of domains that are abstracted and remote from the circumstances in which goal-directed activities of vocational practice are enacted. As others have argued (e.g. Cobb, 1998; Lave, 1993), it is not adequate to merely add contextual factors to cognitive conceptions. Nor is it useful to emphasise social and cultural contributions at the cost of discarding the individual as a significant and interdependence agent (Salomon, 1994). Instead, there are bases for reconciling the cognitive and sociocultural perspectives and important contributions from other disciplines that augment and advance our understanding of thinking, acting and knowing. Consequently, the proposal here sits within concerns that elaborate and reappraise ideas advanced within cognitive psychology (e.g. domains of knowledge, expertise, problem solving) and acknowledge the contributions of both capacities and practice to the formation of expertise and its development by individuals. In doing so, it sits within and contributes to current discussions about the relationships between social practice and individuals acting in social practice, through attempting to avoid the 'twin hazards' of individual constructivism and social determinism (Miller \& Goodnow, 1995). Ultimately, expertise is held to be a product of interdependence between the individual acting and the social practice in which they act: 'knowing in practice'.

Acknowledgements

Expansive thanks to the two anonymous reviewers and editor whose helpful contributions assisted the revision of this paper. 


\section{References}

Alexander, P. A., \& Judy, J. E. (1988). The interaction of domain specific and strategic knowledge in academic performance. Review of Educational Research, 58 (4), 375-404.

Alexander, P. A., Schallert, D. L., \& Hare, V. C. (1991). Coming to terms: How researchers in learning and literacy talk about knowledge. Review of Educational Research, 61 (3), 315-343.

Beven, F. (Ed.). (1997). Learning in the Workplace: Airline Customer Service. Brisbane, Australia: Centre for Learning and Work Research, Griffith University.

Billett, S. (1995a). Structuring Knowledge Through Authentic Activities. Unpublished PhD thesis. Brisbane, Australia: Griffith University, Faculty of Education.

Billett, S. (1995b). Skill Formation in Three Central Queensland Coal Mines: Reflections on Implementation and Prospects for the Future. Brisbane, Australia: Centre for Research into Employment and Work, Griffith University.Billett, S. (1999). Experts' ways of knowing. Australian Vocational Education Review, 6 (2), 25-36.

Billett, S. (1996). Situated learning: Bridging sociocultural and cognitive theorising. Learning and Instruction, 6 (3), 263-280.

Billett, S. (1997). Dispositions, vocational knowledge and development: Sources and consequences. Australian and New Zealand Journal of Vocational Education Research, 5 (1), 1-26.

Billett, S. (1998). Situation, social systems and learning. Journal of Education and Work, 11 (3), 255-274.

Carraher, T. N., Carraher, D. W., \& Schliemann, A. D. (1985). Mathematics in the streets and in schools. British Journal of Developmental Psychology, 3, 21-29.

Ceci, S. J., \& Liker, J. K. (1986). A day at the races: A study of IQ, expertise and cognitive complexity. Journal of Experimental Psychology: General 115, 225-266.

Chase, W. G., \& Simon, H. A. (1973). The mind's eye in chess. In W.G. Chase (Ed.) Visual Information Processing. New York: Academic Press.

Chi, M. T. H. (1978). Knowledge structures and memory development. In R. Siegler (Ed.). Children's thinking: What develops? (pp. 73-96). Hillsdale, NJ: Erlbaum.

Chi, M. T. H., Feltovich, P. J., \& Glaser, R. (1981). Categorisation and representation of physics problems by experts and novices. Cognitive Science, 5, 121-152.

Chi, M. T. H., Glaser, R., \& Farr, M. J (1982). The Nature of Expertise. Hillsdale, NJ: Erlbaum.

Cobb, P. (1998). Learning from distributed theories of intelligence. Mind, Culture and Activity, 5 (3), 187-204.

Cole, M. (1998). Can cultural psychology help us think about diversity? Mind, Culture and Activity, 5 (4), 291-304.

Engestrom, Y. (1993). Development studies of work as a testbench of activity theory: The case of primary care medical practice. In S. Chaiklin \& J. Lave (Eds.), Understanding Practice: Perspectives on Activity and Context. (pp. 64-103). Cambridge: Cambridge University Press.

Engestrom, Y. \& Middleton, D. (1996) Introduction: Studying work as mindful practice. In Y Engestrom \& D. Middleton (Eds.), Cognition and Communication at Work. (pp.1-15). Cambridge: Cambridge University Press.

Ericsson, K. A., \& Lehmann A. C. (1996). Expert and exceptional performance: Evidence of maximal adaptation to task constraints. Annual Review of Psychology, 47, 273-305.

Ericsson, K. A., \& Simon, H. A. (1984). Protocol Analysis - Verbal Reports as Data. Cambridge, MA: MIT Press.

Ericsson, K. A., \& Smith, J. (1991). (Eds.), Towards a General Theory of Expertise: Prospects and Limits. Cambridge: Cambridge University Press.

Fuhrer, U. (1993). Behaviour settings analysis of situated learning: the case of newcomers. In S. Chaiklin \& J. Lave (Eds.), Understanding Practice: Perspectives on Activity and Context (pp. 179-211). Cambridge: Cambridge University Press.

Gelman, R., \& Greeno, J. G. (1989). On the nature of competence: Principles for understanding in a domain. In L. B. Resnick (Ed.), Knowing, Learning and Instruction: Essays in Honor of Robert Glaser (pp. 125-186). Hillsdale, NJ: Lawrence Erlbaum Associates.

Glaser, R. (1984). Education and thinking - the role of knowledge. American Psychologist, 39 (2), 93104. 
Glaser, R. (1990). Re-emergence of learning theory within instructional research. American Psychologist, 45 (1), 29-39.

Goodnow, J. J. (1990). The socialisation of cognition: what's involved? In J. W. Stigler., R.A. Shweder., \& G. Herdt (Eds.), Cultural Psychology. (pp. 259-86). Cambridge: Cambridge University Press.

Gott, S. (1989). Apprenticeship Instruction for Real-World Tasks: The coordination of procedures, mental models and strategies. In E. Z. Rothhopf, (Ed.), Review of Research in Education 15, 97-169

Greeno, J. (1997). On claims that answer the wrong questions. Educational Researcher, 26 (1), 5-17.

Groen, G. J., \& Patel, P. (1988). The relationship between comprehension and reasoning in medical expertise. In M. T. H. Chi, R. Glaser \& R. Farr (Eds.), The Nature of Expertise (pp. 287-310) Hillsdale, NJ: Erlbaum.

Hodges, D. C. (1998). Participation as dis-identification with/in a Community of practice. Mind, Culture and Activity, 5 (4), 272-290.

Hutchins, E. (1991). The social organization of distributed cognition. In L. B. Resnick, J. M. Levine \& S. D. Teasley (Eds.), Perspectives on Socially Shared Cognition. (pp.283-307) Washington DC: American Psychological Association.

Hutchins, E., \& Palen, L. (1997). Constructing meaning from spaces, gesture, and speech. In L. B. Resnick, C. Pontecorvo \& R. Saljo (Eds.), Discourse, Tools and Reasoning: Essays on Situated Cognition. (p.23-40). Berlin: Springer.

Laufer, E. A., \& Glick, J. (1996). Expert and novice differences in cognitive activity: A practical work activity. In Y Engestrom \& D. Middleton (Eds.), Cognition and communication at work. (pp. 177-198). Cambridge: Cambridge University Press.

Lave, J. (1990). The culture of acquisition and the practice of understanding. In J. W. Stigler, R.A. Shweder., \& G. Herdt (Eds.), Cultural Psychology (pp. 259-86). Cambridge: Cambridge University Press.

Lave, J. (1991). Situated learning in communities of practice. In L. B. Resnick, J. M. Levine, \& S. D. Teasley (Eds.), Perspectives on Socially Shared Cognition. (pp.63-82). Washington DC: American Psychological Association.

Lave, J. (1993). The practice of learning. In S. Chaiklin \& J. Lave (Eds.), Understanding Practice: Perspectives on Activity and Context (pp. 3-32). Cambridge: Cambridge University Press.

Lave, J. \& Wenger, E. (1991). Situated Learning - Legitimate Peripheral Participation. Cambridge: Cambridge: University Press.

Lesgold, A. (1989). Towards intelligent systems for testing. In L. B. Resnick (Ed.) Knowing, Learning and Instruction: Essays in Honor of Robert Glaser (pp. 337- 360) Hillsdale, NJ: Lawrence Erlbaum Associates.

Miller, P. J., \& Goodnow J. J. (1995). Cultural practices: Towards an integration of culture and development. In J. J. Goodnow, P. J. Miller \& F. Kessel (Eds.), Cultural Practices as Contexts for Development, New Directions in Child Development, 67. (pp. 5-16) San Francisco: Jossey Bass.

Newman, D., Griffin, P., \& Cole, M. (1989). The Construction Zone: Working for Cognitive Change in Schools. Cambridge: Cambridge University Press.

Pea, R. D. (1993). Learning scientific concepts through material and social activities: Conversational analysis meets conceptual change. Educational Psychologist 28 (3), 265-277.

Pelissier, C. (1991). The anthropology of teaching and learning. Annual Review of Anthropology, 20, 75-95.

Piaget, J. (1966). Psychology of Intelligence. Totowa, NJ: Littlefield, Adam \& Co.

Prawat, R. S (1989). Promoting access to knowledge, strategy, and dispositions in students: A research synthesis. Review of Educational Research, 59 (1), 1-41.

Prawat, R. S., \& Floden, R. E. (1994). Philosophic perspectives on constructivist views of learning. Educational Psychologist, 29 (1), 37-48.

Resnick, L. B, Levine, J. M., \& Teasley, S. D. (1991). (Eds.), Perspectives on Socially Shared Cognition. (pp.63 -82). Washington DC: American Psychological Association. 
Resnick, L. B., Pontecorvo, C., \& Saljo, R. (1997). Introduction. In L. B. Resnick, C. Pontecorvo \& R. Saljo (Eds.), Discourse, Tools and Reasoning: Essays on Situated Cognition. (pp120). Berlin: Springer.

Rogoff, B. (1990). Apprenticeship in Thinking - Cognitive Development in Social Context. New York: Oxford University Press.

Rogoff, B. (1995). Observing sociocultural activities on three planes: participatory appropriation, guided appropriation and apprenticeship. In J. V. Wertsch, P. Del Rio \& A. Alverez (Eds.), Sociocultural Studies of the Mind (pp. 139-164). Cambridge: Cambridge University Press.

Ryle, G. (1949). The Concept of Mind. London: Hutchinson University Library.

Säljö, R. (1999). Concepts, cognition and discourse: From mental structures to discursive tools. In W. Schnotz, S. Vosniadou \& M. Carretero (Eds.) New Perspectives on Conceptual Change. Amersterdam: Pergamon.

Salomon, G. (1994). Whole individuals in complex settings: Educational research reexamined. Invited address - Newcastle, NSW, November. Annual Meeting of the Australian Association for Research in Education.

Scandura, J. M. (1980). Theoretical foundations of instruction: A systems alternative to cognitive psychology. Journal of Structural Learning, 6, 347-394.

Schraagen, J. M. (1993). How expert solve a novel problem in experimental design. Cognitive Science, 17, 285-309.

Schon, D. A. (1983). The Reflective Practitioner: HowProfessionals Think in Action. New York: Basic Books.

Scribner, S. (1985). Vygotsky's use of history. In J. V. Wertsch (Ed.), Culture, Communication and Cognition: Vygotskian Perspectives (pp. 119-145). Cambridge: Cambridge University Press.

Scribner, S. (1997/1988). Mental and manual work: An activity theory orientation. In E. Tobah, R. J. Falmagne, M. B. Parlee, L. M. Martin \& A. S. Kapelman (Eds.), Mind and Social Practice: Selected Writings of Sylvia Scribner. (pp 367-374).Cambridge. UK: Cambridge University Press

Scribner, S., \& Beach, K. (1993). An activity theory approach to memory. Applied Cognitive Psychology, 7, 185-190.

Simon, H. A., \& Gilmartin, K. A. (1973). A simulation of memory for chess positions. Cognitive Psychology, 5, 29-46.

Stevenson, J. (Ed.). (1996). Learning in the workplace: Tourism and Hospitality. Brisbane, Australia: Centre for Skill Formation Research and Development, Griffith University.

Stigler, J. W., Barclay, C., \& Aiello, P. (1982). Motor and mental abacus skills: A preliminary look at an expert. Quarterly Newsletter of the Laboratory of Comparative Human Cognition, 4, 1214.

Suchman, L. (1996). Constituting shared workspaces. In Y. Engestrom \& D. Middleton (Eds.), (1996) Cognition and Communication at Work. (pp.35-60). Cambridge, UK: Cambridge University Press.

Suchman, L. (1997). Centers of coordination: A case and some themes. In L. B. Resnick, C. Pontecorvo \& R. Saljo (Eds.), Discourse, Tools and Reasoning: Essays on Situated Cognition. (pp.41-62). Berlin: Springer.

Sweller, J. (1989). Should problem solving be used as a learning device in mathematics? Journal of Research into Mathematics Education, 20 (3), 321-28.

Trogon, A., \& Grusenmeyer, C. (1997). To resolve a technical problem through conversation. In L. B. Resnick, C. Pontecorvo \& R. Saljo (Eds.), Discourse, Tools and Reasoning: Essays on Situated Cognition. (pp.87-110). Berlin: Springer.

Valsiner, J. (1994). Bi-directional cultural transmission and constructive sociogenesis. In W.de Graaf \& R. Maier (Eds.), Sociogenesis Re-examined (pp. 101-134). New York: Springer.

Voss, J. F., Tyler, S. \& Yengo, L. (1983). Individual differences in the solving of solving of social science problems. In R. Dillion \& R. Schmeck (Eds.), Individual Differences in ProblemSolving. San Diego, CA: Academic Press.

Vygotsky, L. S. (1978). Mind in Society - the Development of Higher Psychological Processes. Cambridge: Harvard University Press. 
Wagner, R. K., \& Sternberg, R. J. (1986). Tacit knowledge and intelligence in the everyday world. In R. J. Sternberg, \& R. K. Wagner (Eds.), Practical Intelligence - Nature and Origins of Competence in the Everyday World (pp. 51-83), Cambridge: Cambridge University Press.

Wenger, E. (1998). Communities of Practice: Learning, Meaning, and Identity. Cambridge: Cambridge University Press.

Wertsch, J. W. (1991). A sociocultural approach to socially shared cognition. In L. B. Resnick, J. M. Levine \& S. D. Teasley (Eds.), Perspectives on Socially Shared Cognition. (pp 85-100). Washington, DC: American Psychological Association.

Wertsch, J. W. (1998). Mind as Action. New York: Oxford University Press. 